\title{
On the Nature of Meaning and Untranslatability
}

\author{
Huang Saisai
}

School of Foreign Languages, Zhejiang University of Finance \& Economics Dongfang College, Haining, 314408 PRC China

Received: 15 May 2021; Received in revised form: 09 Jun 2021; Accepted: 20 Jun 2021

(C2021 The Author(s). Published by TheShillonga. This is an open access article under the CC BY license

(https://creativecommons.org/licenses/by/4.0/)

\begin{abstract}
The nature of meaning has long been the focus of the study of the philosophy of language. In this paper, the relationship between language and the mind is talked in a detailed way by mentioning Saussure's account of meaning and language that people see the world according to the structure of the language they have learnt. And the development of Saussure's idea by Sapir and Whorf, linguistic determinism and its weaker version, linguistic relativity is stated especially by relating it with the notion of untranslatability. Then an instance of a loss or distortion of translation is quoted to defend untranslatability.
\end{abstract}

Keywords - meaning, language, untranslatability

\section{INTRODUCTION}

It's generally true that much of our current thinking about language has its origin in ideas put forward by philosophers. So it's not surprising that there is much philosophy in linguistics. Philosophy of Language is mainly organized around general questions of language and meaning, the discussion of which abound in both philosophy and linguistics. Meaning is of central importance to all branches of philosophy concerned with the study of language. The nature of meaning has long been an obsession of philosophers, and also more specific problems that arise in understanding the nature of meaning have also become the focus of language studies. And it is the general theme to string together all the topics concerned with the philosophical aspects of language.

\section{AN OVERVIEW OF THE UNDERSTANDING OF THE NATURE OF MEANING}

Philosophers of language inquire into the nature of meaning and seek to explain what it means to "mean" something. And the first concern is the relationship between words and things. One of the earliest points of discussion that whether words can in fact be said to refer directly to things has remained central and the answers to this lead to two approaches to meaning: ideational account of meaning and direct reference of meaning. Therefore, meaning can be described in terms of denotation and connotation or in the similar distinction extension and intension. When words are combined into sentences, the meaning of sentences can also be dealt with in the same way. And this can be found in the work of Gottlob Frege. "He proposes that the sense of a sentence is a particular 'thought' and describes that the 'truth-value of a sentence as constituting what it means."' (qtd. in Chapman 44) So it follows that the extension of a sentence is its truth-value and the intension of a sentence is often described as a proposition. The internal structure of propositions is described in terms of predicate logic, while the ways simple propositions combine together to form compound propositions are referred as propositional logic. These act as a system for describing the truth-functional properties of sentences. Yet in order to give a full account of language, how a proposition can determine the extension of the sentence should not be neglected. One way to consider the question is to look at the specific circumstances to hold for it to be true, which is defined as a 'truth-conditional' account of meaning. "Another truth-based account of meaning known as possible world semantics suggested 
that meaning can be defined in terms of truth, but only with reference to the totality, or set of possible words in which a sentence is true." (Chapman 74) However, truth-conditional accounts cannot solve the problems raised by evidence that meaning is determined as much by how language is used as by semantic content. For some philosophers, language is a system primarily used by human beings to interact with each other. For them, meaning is determined not just by the rules which explain a language and relate it to the world, but also by a whole variety of factors labeled extra-linguistics. The use of everyday speech, and attitudes and intentions of speakers are also relevant focuses of philosophical analysis. The studies they engage in later become known as the ordinary language philosophy. J.L.Austin, who first used the term descriptive fallacy suggested that it would be more useful to describe language as a means of doing things. And most significantly, Wittgenstein put forward the idea that "the meaning of the word is its use in the language". "It's best to consider any given word as having not one fixed meaning, but 'a family of meaning." (qtd. in Chapman 113) The new empiricists in twentieth century rejected metaphysical speculation about mental states, and even about abstract meaning in favor of observable phenomena of language use. Quine claims that it simply isn't necessary to posit a notion of "meaning", "meanings themselves, as obscure intermediaries entities, may well be abandoned." (qtd. in Chapman 113) Meaning is dependent on the use of expression and on the use of every other expression in the language. This approach leads to the discussion of the nature of language and the relationship between language and the mind or of mental processes, since language is so intimately bound up with the way we understand, describe and affect the world around us.

Sausurre's influence on the study of language can never be too overemphasized. He rejects the extensional account of meaning and argues that language consists of a series of signs which combine a concept, signified and the sound-image associated with it, signifier. And the relationship between signifier and signified is arbitrary. What's more, each sign is significant only in how it relates to and differs from the other signs of language. So the meaning of an individual word depends primarily not on something external to the language system but on the system itself. "Language doesn't simply nominate objects or concepts that have already come into being, but it creates its own signified." (Chen 67) For example, the concept of the color red in English cannot find its counterpart in French. The French translation rouge should first be considered in terms of its gender, and then it is referred as le rouge as a masculine. And this division doesn't occur in English. Furthermore, the difference is made more significantly when the connotations of red and le rouge are taken into consideration. The difference between the two French synonyms "partir" and "sortir" which both means "go out, leave for" in English is that "partir" is usually followed by a place while "sortir" stresses the state of being out. However, there is no similar synonymous verb pair in English. Therefore, different languages create their own signifier, so the individual concepts are brought into being by the language. "Setting aside its expression in words, our thought is simply a vague, shapeless mass... no ideas are established in advance, and nothing is distinct, before the introduction of linguistic structure." (Saussure 159) Saussure argues that the concepts can't exist independently of prior to our language. In other words, people have access to certain concepts, and therefore see the world according to the structure of the language they have learnt.

Saussure's idea about the relationship between language and thought was later developed by Sapir and Whorf into the theory known as linguistic determinism. The theory of linguistic determinism states that the way in which an individual thinks and perceives the world is dependent on his or her language. Sapir's student Benjamin Lee Whorf came to be seen as the primary proponent of this hypothesis as a result of his published observations of how he perceived linguistic differences to have consequences in human cognition and behavior. Sapir has mentioned an interesting case to state that people speaking different languages with distinct grammatical structures see the world in a different way. Suppose all the people were presented with a scene, in which a stone falls, they would describe the same event differently in accordance with their own language. People speaking English will first divide this event into two parts, "stone" the object and "falls down" the act. And people speaking French will first take the word "stone" as a feminine word, while people 
speaking German will take it as a masculine word. All these languages need to determine whether the object stone is used in definite reference or in indefinite reference, and in each case it would be referred as "a stone" or "the stone", "une pierre" or "la pierre", "ein tein" or "der stein". However, it's irrelevant in Russian. Speakers of the Kwakiutl language specify through their own linguistic structures whether or not the stone is visible or invisible to the speaker at the time of "falling," whether it is nearer to the speaker, the hearer or someone else. The Kwakiutl language does not specify if it is one stone or several stones, nor does it specify the time of the fall. People speaking Nootka will see the whole event in a quite different way. They use a verb indicating the act of a stone falling and a particle indicating the direction of the act instead of using a noun to describe the object. Therefore, people speaking Nootka divide the whole event into an act and the direction of the act. (qtd. in Zhou 8)

\section{THE NOTION OF UNTRANSLATABILITY}

The strong Whorfian view that thought and action are entirely determined by language has long been abandoned in the field. However, the weak version that linguistic categories and usage influence thought and certain kinds of non-linguistic behavior or known as linguistic relativity has enjoyed a considerable resurgence, and much new evidence regarding the effects of language on thought has become available. Boroditsky makes a conclusion about the experiments available to show how different languages shape the speakers' thought. For example, languages differ in the extent to which they make a grammatical distinction between objects and substances. In English, objects like candle and chairs have distinct singular and plural forms (e.g. one candle versus two candles), but substance like mud and wax do not. Instead of saying "one mud, two muds", English speakers must specify the unit of measurement such as "one mound of mud". Unlike English, some languages do not have a grammatical boundary between objects and substances. In Yucatec Mayan, all nouns act almost as if they refer to substances. And several studies suggest that talking about objects as if they were substances in their language lead Yucatec Mayans to attend more to the materials and substances that comprise the objects. English speakers and Yucatec
Mayans were shown an example object and asked to choose which of two other objects was more similar to this example. The two choices varied from the example either in shape or in material. English speakers preferred the shape match, even though they were made of different materials. Yucatec Mayans, on the other hand, preferred the material match. (Boroditsky 3) Findings like this suggest that aspects of grammar can in fact shape the way speakers of a language conceptualize the shapes and materials of objects. Further studies have also found effects of language on people's understanding of numbers, colors, shapes, events and other minds.

Considering the many ways in which language differ, the studies suggest how people who speak different languages may differ in their thought. Languages differ dramatically from one another in terms of how they describe the world, and the categories and distinctions of each language stand for a way of perceiving and analyzing the world. Whorf vividly imagined a natural logician, Mr. Everyman, who reasoned that facts are unlike to speakers whose language background provides for unlike formulation of them. (Whorf 235) The advocates of a strong linguistic relativity position are arguing that the particular metaphysics implicit in a given language is constitutive of experience. "On such a view, it follows that there will be certain things said in one language which are entirely inexpressible in some other language." (Swanson 186) And this leads to the frequently proclaimed dogma of untranslatability. The linguistic relativist's claim is that certain items in the linguistic repertoire of one language are not translatable into some other language. It appears obviously when it comes to the translation of poem which holds in high regard that poetic connotation, emotive value, distinctive flavor, etc. should be carried over from the source language into the target language. And the true case proves the view of linguistic relativity since not only does any poem lose enormously in the translation from the language in which it was written to any other foreign one, but even within a given language, an effort to elaborate a poem can fail. The example that one language defies translation into another can be found in Eugene Nida's remarks on Bible translation. He cites several instances where information which is lacking in the source language has to be added in translation into some other language. 
The following is typical:

For example, in Matthew 4: 13 there is no information available from the New Testament record as to whether Jesus had ever visited Capernaum prior to his trip recorded at this point. When, as in the Villa Alta dialect of Zapotec, spoken in southern Mexico, it is obligatory to distinguish between actions which occur for the first time with particular participants and those which are repetitious, one must make a decision, despite the lack of data in the source language. Since there is greater likelihood that Jesus would have visited nearby Capernaum than that he would not have done so, the translation into Villa Alta Zapotec reflects this probability, and there is accordingly a distinct increase in information in the translation. (qtd.in Swanson 190)

Jakobson suggests that whenever there is deficiency, terminology may be qualified and amplified by loan-words or loan-translations, neologisms or semantic shifts, and finally by circumlocutions. In this case, it is not literary style, or emotional connotation that is considered in the question of translatability but only the possibility to reproduce the message content. And in this sense, his assertion that all cognitive experience and its classification are conveyable in any existing language needs a second thought. Noam Chomsky provides another example for such failure in translation. According to Chomsky, linguistic capacity is dependent upon the mastery of a grammar of a language, the acquisition of which is only made possible because of the language user's innately equipped schema for the construction of such grammars. However, that innate schema not only makes possible the acquisition of a grammar, but it also limits the possible grammars which can be acquired and so in turn places limits on linguistic capacity. Malpas points out that untranslatability intrinsic to the languages involved will only arise if there is some limitation in the linguistic and cognitive resources available. "The untranslatability thesis is thus tied to the idea of there being limits to linguistic and cognitive capacity." (Malpas 235) In this respect, one example of Whorf's suggests that in some cases languages might be essentially untranslatable. Whorf claims that the language of the Hopi Indians lacks altogether a reference to time, and that the notion, so common to speakers of modern European languages, of a linear time flowing in river fashion through the flux of events in space, is entirely lacking to the Hopi culture. "If both were incapable of seeing it as the other did, then obviously an impasse would exist as far as communication is concerned." (qtd. in Swanson 187) It is difficult to decide whether the presence or absence in a given language of time notion can actually constitute a genuine case of untranslatability. But whatever examples could be found would, something like the loss or distortion of information is meant to illustrate the notion of untranslatability.

\section{CONCLUSION}

This paper provides an overview of the understanding of the nature of meaning in language philosophy. Saussure's account of meaning and language, and its later development support the idea that linguistic categories and usage influence thought. The cases in translation projects are also provided to suggest that certain items in the linguistic repertoire of one language are not translatable into some other language.

\section{REFERENCES}

[1] Boroditsky, L. "Linguistic Relativity." Encyclopedia of Cognitive Science. L. Nadel (Ed.).2006

[2] Chapman, Siobhan. Philosophy for Linguists: An Introduction. London and New York: Routledge, 2000

[3] Chen Jiaying. Linguistic Philosophy. Beijing: Beijing University Press, 2006.

[4] Malpas, J. E. "The Intertranslatability of Natural Languages.” Synthese.Mar.1989: 233-264

[5] Whorf, Benjamin Lee. Language, Thought, and Reality. Mass.: Cambridge, 1956

[6] Saussure, Ferdinand de. Course in General Linguistics. 
Beijing: Foreign Language Teaching and Research Press,2001

[7] Swanson, J. W. "Linguistic Relativity and Translation." Philosophy and Phenomenological Research. Dec.1961:185-192

[8] Zhou Zhipei. A Comparison of Chinese and English and their Translation. Shanghai: East China University of Science and Technology Press, 2003. 